\title{
Modelling and Analysis of Energy Harvesting in Internet of Things (IoT): Characterization of a Thermal Energy Harvesting Circuit for IoT Based Applications with LTC3108
}

\author{
Syeda Adila Afghan 1,*(D) and Husi Géza ${ }^{2}$ \\ 1 Faculty of Informatics, University of Debrecen, Kassai útca 26, 4028 Debrecen, Hungary \\ 2 Faculty of Engineering, Department of Mechatronics, University of Debrecen, Ótemető útca 2-4, \\ 4028 Debrecen, Hungary; husigeza@eng.unideb.hu \\ * Correspondence: adila@eng.unideb.hu; Tel.: +36-20-489-3167
}

Received: 16 September 2019; Accepted: 12 October 2019; Published: 13 October 2019

check for updates

\begin{abstract}
This paper presents a simulation-based study for characterizing and analyzing the performance of a commercially available thermoelectric cooler (TEC) as a generator for harvesting heat energy along with a commercial-off-the-shelf (COTS) power management integrated circuit (PMIC); LTC3108. In this model, the transformation of heat was considered in terms of an electrical circuit simulation perspective, where temperature experienced by TEC on both cold and hot sides was incorporated with voltage supply as Vth and Vtc in the circuit. When it comes to modeling a system in a simulation program with an integrated circuit emphasis (SPICE) like environment, the selection of thermoelectric generator (TEG) and extraction methods are not straightforward as well as the lack of information from manufacturer's datasheets can limit the grip over the analysis parameters of the module. Therefore, it is mandatory to create a prototype before implementing it over a physical system for energy harvesting circuit (EHC) optimization. The major goal was to establish the basis for devising the thermal energy scavenging based Internet of Things (IoT) system with two configurations of voltage settings for the same TEG model. This study measured the data in terms of current, voltage, series of resistive loads and various temperature gradients for generating the required power. These generated power levels from EHC prototype were able to sustain the available IoT component's power requirement, hence it could be considered for the implementation of IoT based applications.
\end{abstract}

Keywords: thermoelectric generator; energy harvesting; LTSpice simulation; LTC3108; internet of things; spice model

\section{Introduction}

Autonomous devices have expanded the way we connect, exchange, communicate and operate around the globe, from smartwatches to medical implant devices, from self-directed car parking to industrial smart machines, all of these comes under one revolutionary term i.e., Internet of Things (IoT) [1,2]. It was reported in 2006 that the number of devices exchanging information via the internet had surpassed the human population [3]. However, there is one typical aspect which is holding back this evolving technology i.e., the need for uninterrupted power. Despite battery support and various power management techniques that have been applied to reduce power consumption, this pervasive technology still faces the dead end. Not only from this but also energy crises due to limited fossil fuels [4] have emphasized the need to make a way out for alternative and green energy solutions. In order to support the demand for continuous power, Energy harvesting $(\mathrm{EH})$ is the solution to 
acknowledging the electric energy requirement and extending the life of wireless sensor nodes (WSN), miniaturized autonomous devices, wearable products or IoT devices. In fact, energy harvesting is the process of converting low-level ambient energy sources into electrical power [5].

Among all available energy sources, which are categorized as renewable energy [6] and residual energy [7], the utilization of heat energy has obtained considerable attention as a viable option for supporting IoT due to its rich availability in domestic or industrial domains. For harvesting heat energy, this process mainly depends on the operation of a thermoelectric generator (TEG) composed of the Seebeck effect that converts the heat energy into electrical energy [8]. One critical factor to consider is that TEGs are only limited to use in micro-harvesting applications due to their low conversion efficiency, which is not more than $12 \%$, so practically they are supporting low-powered devices as a promising solution [9]. For analyzing the efficiency of a TEG, a parameter called Figure-of-merit (ZT) was tested, where the higher ZT corresponded to the higher efficiency of a TEG [9]. Various contributions have been inducted by researchers to enhance the ZT for many industrial and energy related applications, with one of the proposed reports for increasing the ZT to around 2 [10]. Recently, the maximum of ZT experimented was about 2.6, corresponding to maximum thermoelectric conversion efficiency of almost $20 \%$ [11]. However, the advancement in nanotechnology, innovative structure and recent developments in nanomaterials can possibly support the achievement of a higher conversion rate [12]. In terms of low-powered solutions in wearables, many prototypes have been reported that operate from extremely low voltages, with tens of $\mathrm{mV}$ due to small temperature gradients, specifically, powering sensors [13] and wrist watches [14] from human heat. Another solution in wearable thermoelectric devices were established where TEGs could produce up to $20 \mu \mathrm{Wcm}^{-2}$ of usable energy during operation [15].

There is considerable need for research work aimed at analyzing the TEGs performance when it comes to implementing thermal energy along with a power management integrated circuit (PMIC) to support IoT power requirements. The main goal of this simulation-based research work was to enlighten the end users and engineers with a step by step procedure for prototyping a thermal energy harvesting circuit (EHC) along with PMIC and characterization of extracted power over a complicated system. A lot of effort has been invested to carrying out extensive simulation experiments under various scenarios for extracting as much power as possible from TEG, thus validating their suitability when applied to thermal energy harvesting intended for powering IoT based wearable devices.

\section{Internet of Things (IoT) Power Requirements}

In order to establish the basis for comparison, it is mandatory to understand the IoT components' power consumption criterion. The basic elements for any IoT device are a sensor and a microcontroller unit (MCU), which allows power to initiate the process. However, there are various types of sensors with different power requirements as shown in Table 1 [16] and MCUs with different operating frequencies and power consumptions, highlighted in Table 2 [17]. Therefore, it is pointless to make general thresholds for power consumptions in any IoT components due to their dynamic operation and different states, which are continuously changing depending upon the system design and purpose of the application.

Table 1. Sensor types and their powering requirements.

\begin{tabular}{cc}
\hline Sensor Type & Power Consumption \\
\hline Gas sensor & $500 \mathrm{~mW}-800 \mathrm{~mW}$ \\
Image sensor & $150 \mathrm{~mW}$ \\
Pressure sensor & $10 \mathrm{~mW}-15 \mathrm{~mW}$ \\
Acceleration sensor & $3 \mathrm{~mW}$ \\
Temperature sensor & $0.5 \mathrm{~mW}-5 \mathrm{~mW}$ \\
\hline
\end{tabular}


Table 2. Comparison of average power consumption for microcontroller units (MCUs).

\begin{tabular}{|c|c|c|c|c|c|c|}
\hline Performance Metrics & NV-MCU & JSSC2017 & ISSCC2016 & VLSI2015 & ISSCC2015 & ISSCC2014 \\
\hline Architecture & $\begin{array}{l}\text { Cortex-M0 } \\
32 \text { bit }\end{array}$ & $\begin{array}{l}\text { Cortex-M0 } \\
32 \text { bit }\end{array}$ & 80518 bit & $\begin{array}{l}\text { MSP430 } \\
16 \text { bit }\end{array}$ & $\begin{array}{l}\text { MSP430 } \\
16 \text { bit }\end{array}$ & $\begin{array}{l}\text { MSP430 } 16 \\
\text { bit }\end{array}$ \\
\hline Frequency [MHz] & 200 & 30 & 100 & 25 & 16 & 20 \\
\hline Active power $[\mu \mathrm{W} / \mathrm{Mhz}]$ & 26.7 & 28.92 & 33 & 33 & 28.3 & 145 \\
\hline Standby power $[\mu \mathrm{W}]$ & 0.7 & 0.009 & N/A & 0.7 & 0.32 & 1.2 \\
\hline $\begin{array}{c}\text { Average power@ } \\
\text { intermittent operation }[\mu \mathrm{W}]\end{array}$ & 47.14 & 143.3 & $>2900$ & 583.2 & 499.8 & 2560 \\
\hline
\end{tabular}

\section{Methodology}

There were various steps involved in analyzing the thermal EHC-incorporated with LTC3108 PMIC. For modelling a commercially available TEG device, we needed to extract the parameters of selected TEG's and then its electrical model was developed on a LTSpice simulator. One important factor to consider here is that the whole simulation and extraction was based in terms of an electrical perspective, whereas thermal aspects were beyond the scope of this research. However, thermal characteristics were considered in the TEG model simulation as constant parameters.

\subsection{Thermoelectric Generator Model}

To analyze the performance of TEG based on energy harvesting circuitry, it was mandatory to simulate the whole system before implementing it. However, for selection of TEG there were a few points to contemplate, as target applications are based on human body heat harvesting, which usually works under lower temperature gradients as well as the economical cost, which is crucial. TECs can mostly be used as TEGs based on the aforementioned factors. These parameters were verified in this work [18], where an experimental and simulation study was conducted to compare TEC with TEG. In this research, TEC (TEC1-12706) [19] and TEG (GSM250-127-14-10) [20] were analyzed based on similarities and differences for addressing the question that when to replace expensive TEGs with TECs. The experimental analysis was being carried out for output power generation of both modules at different temperature range and same conditions. However, data revealed that the power generation for both modules was almost identical under the temperature range of $0^{\circ} \mathrm{C}$ to $100{ }^{\circ} \mathrm{C}$. This result also proved that the performance of TEC was slightly better than TEG at a lower temperature range of $20^{\circ} \mathrm{C}$ to $40{ }^{\circ} \mathrm{C}$ and has supported a wide variety of applications for EHS. By considering these factors, the model was selected from the same series of TEC i.e., TEC1-12722 [21]. This model was simulated based on specific operating conditions and maximum power ratings for evaluating how they adjust and relate their performance in terms of feasibility, characteristics and load capacity.

\subsubsection{Thermoelectric Generator SPICE Model Selection}

Considering the electrical perspective of the simulation study, the selection of model must be simpler and easier to implement on SPICE-like simulators. In this regard, various simulation-based TEG models have been studied and analyzed $[9,22-24]$ however, due to the scope of this work, which was purely electrical circuit simulation, the electrical parameters for power generation were focused on. Another feature involved in selection of such models is their capacity to abstract parameters from a manufacturer's datasheet. This was the major limitation when working with mostly TECs and TEGs as most of the information is not revealed by manufacturers. Based on such limitations, two models that have been under analysis, supported this concept; Kubov's model [25] and the Moumouni's model [26] where their spice model for TEG was presented. According to our research requirement, Kubov's model was selected due to its simplicity and small set of variables. This model has two segments, the upper one represents the electrical part and the lower one belongs to the thermal part as shown in Figure 1. 

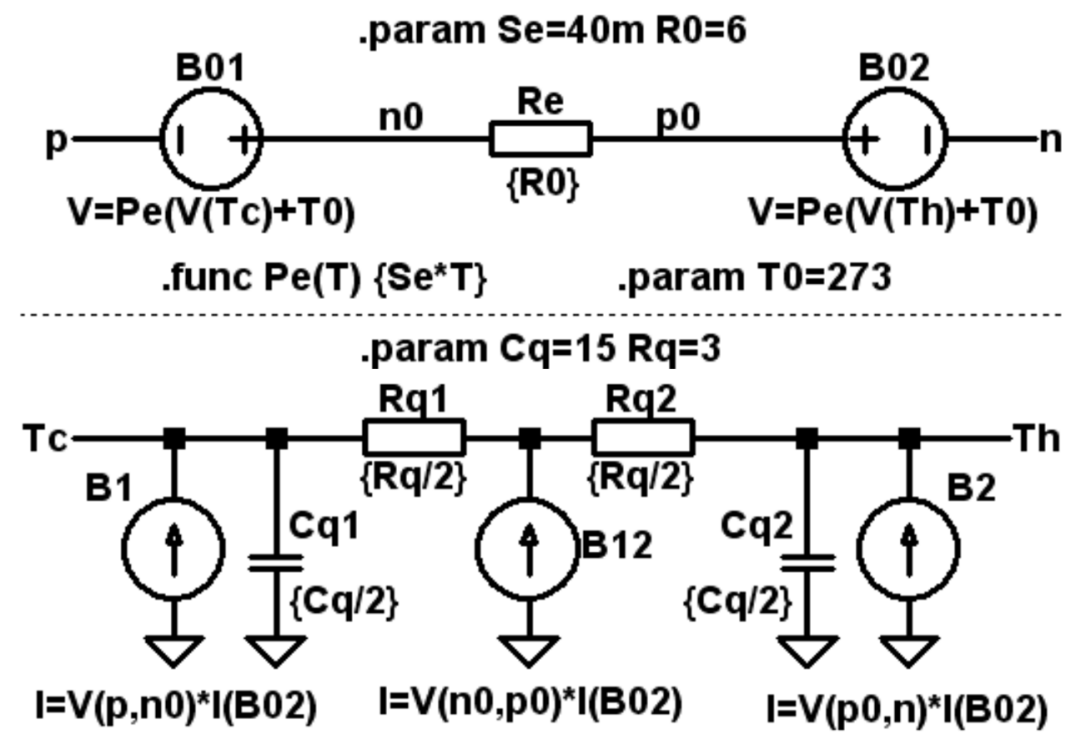

Figure 1. Kubov's LTspice TEG model; Top part: Electrical, Bottom part: Thermal.

The thermal part defines the current as an equivalent of thermal power whereas, voltage is defined as an equivalent of temperature. In this configuration the electrical contact B01 was switched in reverse towards the current direction (absorption of heat), while contact B02 was in a straight direction (generation of heat). Therefore, heat transferred from the cold to hot side and this heat was described as the Peltier coefficient.

The heat parameter as a Peltier coefficient $(\mathrm{Pe})$ is defined by the following function and was enlisted inside the netlist of the simulation model

$$
\text { .func } P e(T)\{\mathrm{Se} * \mathrm{~T}\}
$$

where Seebeck coefficient is represented by Se and absolute temperature is denoted by T.

\subsubsection{Parameter Extraction from the Datasheet}

As mentioned earlier, the selection of the spice model was based on the way the parameters were extracted from the datasheet and in this regard, Kubov's model was chosen for simulation. This model only required four parameters for simulation, which were Seebeck coefficient (Se), electrical resistance $\left(\mathrm{R}_{\mathrm{TEG}}\right)$ thermal resistance $(\mathrm{Rq})$ and heat capacity $(\mathrm{Cq})$. The first two parameters belonged to the electrical aspect and the remaining two defined thermal characteristics. The electrical parameters are elaborated on in this section through a seven-step approach defined by Kubov whereas, thermal parameters were considered as generalized values. The nominal values of $\mathrm{Rq}$ and $\mathrm{Cq}$ were experimented in three variations to analyze the impact of temperature dependence [25], where thermal values were two times lesser and two times higher than the selected ones. For internal thermal resistance, the measured values were $(\mathrm{Rq}=1.5,3.0,6.0)$, and the same process was done for thermal capacity $(\mathrm{Cq}=7.5,15,30)$. Therefore, we considered the mid-range as a generalized value of thermal parameters for our model.

For electrical parameter extraction, the seven-step approach was utilized to abstract and calculate TEG internal resistance, Seebeck coefficient, and thermal resistance as required parameters from the datasheet [27]. As we only focused on electrical power generation from TEG, only two parameters, Se and $\mathrm{R}_{\mathrm{TEG}}$ came under consideration.

In order to determine the electrical parameters (Se, $\mathrm{R}_{\mathrm{TEG}}$ ) of TEC1-12722, there were necessary calculations to be made. The extraction and calculation results were verified experimentally by the author in [25]. The following procedure is applied for calculating the parameters from manufacturer's datasheet. 
Steps can be itemized by:

1. Reading and observing the maximum output voltage $\left(V_{O P T}\right)$ of the TEC1-12722 module:

$$
V_{\text {OPT }} \text { value is } 16 \mathrm{~V} \text { for } \mathrm{T}_{\mathrm{h}}=27^{\circ} \mathrm{C}
$$

2. Calculating the Seebeck Coefficient (Se):

$$
\begin{gathered}
\text { Se }=\frac{\mathrm{V}_{\mathrm{O}^{\prime} \mathrm{pt}}\{\mathrm{V}\}}{\mathrm{T}_{\mathrm{h}}\langle\mathrm{K}\}} \\
\mathrm{Se}=\frac{16}{27+273}=53 \mathrm{mV} / \mathrm{K}
\end{gathered}
$$

3. Determining the maximum performance for a zero temperature difference:

$$
\mathrm{Q}_{\text {Cold }}=185 \mathrm{~W}
$$

4. Calculating Electrical resistance $\left(\mathrm{R}_{\mathrm{TEG}}\right)$ :

$$
\begin{gathered}
\mathrm{R}_{\mathrm{TEG}}=\frac{\mathrm{v}_{\mathrm{Opt}}{ }^{2}}{2 \cdot \mathrm{Q}_{\mathrm{Cold}}} \\
\mathrm{R}_{\mathrm{TEG}}=\frac{16^{2}}{2.185}=0.692 \Omega
\end{gathered}
$$

The calculated parameters were initialized in Kubov's model, which required four constraints to process the TEG simulation, as two of the parameters were already extracted; $\mathrm{R}_{\mathrm{TEG}}$ and Se related to power generation, whereas, the remaining two parameters belonged to the thermal characterization (Thermal resistance $\mathrm{Rq}$ and Thermal capacity $\mathrm{Cq})$; these parameters were selected as $(\mathrm{Rq}=3)$ and $(\mathrm{Cq}=15)$, as the generalized values selected out of three variations of thermal parameters. The model is demonstrated along with parameter values in Figure 2.
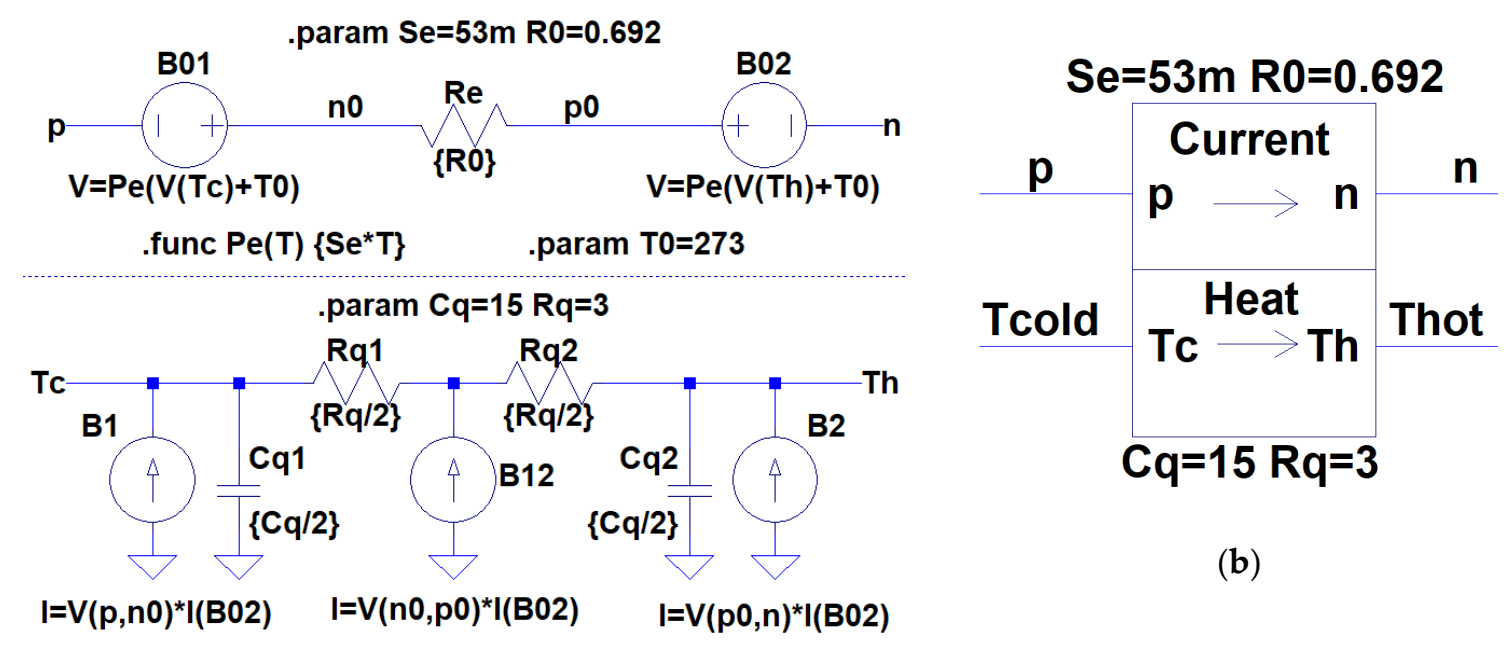

(b)

(a)

Figure 2. (a) Kubov's LTspice TEG model; (b) Subcircuit of TEC1-12722 along with calculated parameters.

\subsection{LTSpice Simulation For Thermal Energy Harvesting Circuit With LTC3108}

In order to interface between the EH source and output load, a power converter was required. As any harvested source is unable to produce operational output therefore, a power converter was needed to transform lower input level into desired output levels. However, for thermal EHC, a step-up power converter LTC3108 PMIC [28] was chosen. The selection of this PMIC was based on specific reasons, as this IC was explicitly designed for EHC setup to harvest low efficiency thermal input and it 
had the lowest cold start activation voltage as low as $20 \mathrm{mV}$. Apart from this, it also gave four $\mathrm{V}_{\text {OUT }}$ settings to work with, which made it ideal for our research profile. As stated by the LTC3108 datasheet, the main output was programmed to one of four fixed voltages to power a wireless transmitter or a sensor. Out of four $V_{\text {OUT }}$ settings $(2.3,3.3,4.1,5)$, we worked on the first two fixed voltages for analyzing the difference in power generation curves and response of the PMIC itself. The situation, which was considered in terms of PMIC output voltage settings was that, at what temperature range and on what load configuration the PMIC could sustain the output, which was fixed under two different $\mathrm{V}_{\text {OUT }}$ settings $(2.3 \mathrm{~V}, 3.3 \mathrm{~V})$.

Considering these aspects, the simulation results were experimented under two scenarios: Analyzing the performance curves at (a) $\mathrm{V}_{\text {OUT }}=2.3 \mathrm{~V}$ and (b) $\mathrm{V}_{\text {OUT }}=3.3 \mathrm{~V}$.

The initial setup can be seen in Figure 3.

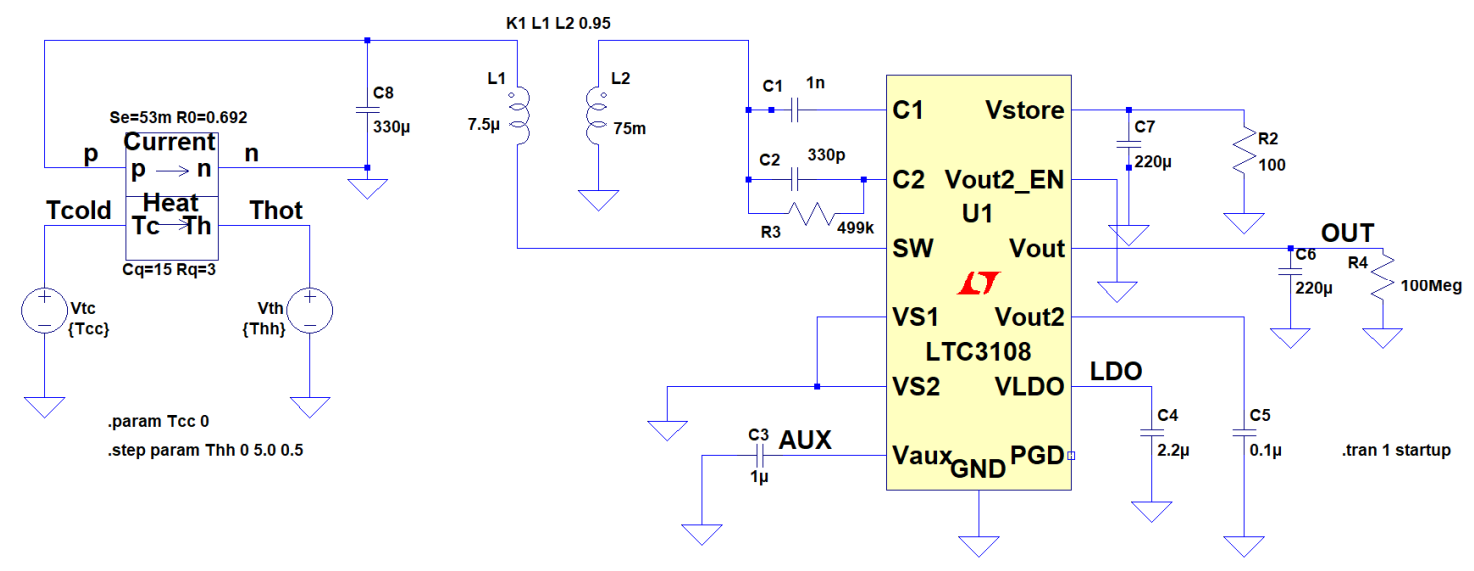

Figure 3. Thermal Energy Harvesting Circuit of TEC1-12722 with LTC3108 PMIC.

\section{Thermal Energy Harvesting Circuit Characterization and Performance Curves}

For analyzing the performance curves of thermal EHC, the following settings were initialized in the simulation setup; in order to simulate temperature difference on EHC, two voltage supplies stated as Vtc (cold side) and Vth (hot side) were connected with the sub-circuit of TEG. Where Vtc was held at $0{ }^{\circ} \mathrm{C}$ and Vth was sweeped in linear step from $0{ }^{\circ} \mathrm{C}$ to $5{ }^{\circ} \mathrm{C}$ (step size $=0.5^{\circ} \mathrm{C}$ ). The selection of $\mathrm{R}_{\mathrm{LOAD}}$ configuration was based on three distinctions initialized as, small values [50-900; increment of 50], mid values [1000-9000; increment of 1000], and large values [100 k-500 k; increment of $100 \mathrm{k}$ ]. These values were chosen according to the capability of PMIC to sustain the load at 2.3 and $3.3 \mathrm{~V}_{\text {OUT }}$ settings. The upcoming sections have been dedicated to separate settings and observations regarding open circuit testing and performance curves defined at two fixed voltages.

\subsection{Open Circuit Testing}

The developed TEG model that was incorporated with LTC3108 PMIC behaved as a complete EHC simulation setup. The open circuit test consisted of temperature gradient as an input and measuring the electrical output voltage without the load connection. To simulate the open circuit or idling condition, the resistor value of $R_{\mathrm{LOAD}}$ was initialized to $100 \mathrm{M} \Omega$. It can be seen in Figure 4, the open circuit voltage varied linearly with the increase in temperature gradients $\left(\Delta \mathrm{T}=\left(\mathrm{TH}-\mathrm{TC}\left({ }^{\circ} \mathrm{C}\right)\right)\right.$.

\subsection{Setup 1: Setting $V_{\text {OUT }}$ at 2.3 V for Thermal EHC}

The extracted parameters as tabulated in Table 3 were initialized in the thermal EHC and the VS1, VS2 pins were set to GND for $\mathrm{V}_{\text {OUT }}=2.3 \mathrm{~V}$. It is important to highlight that the temperature gradients $(\Delta \mathrm{T})$ would be scaled as low as possible, since for human body heat applications, the observed temperature difference is quite small. For human wearable energy harvesting, the maximum temperature difference 
across TEG is $5{ }^{\circ} \mathrm{C}$ only [29]. Therefore, the simulation setup ranged from $0.5{ }^{\circ} \mathrm{C}$ to a maximum of $5.0^{\circ} \mathrm{C}$ with an incremental step of 0.5 .

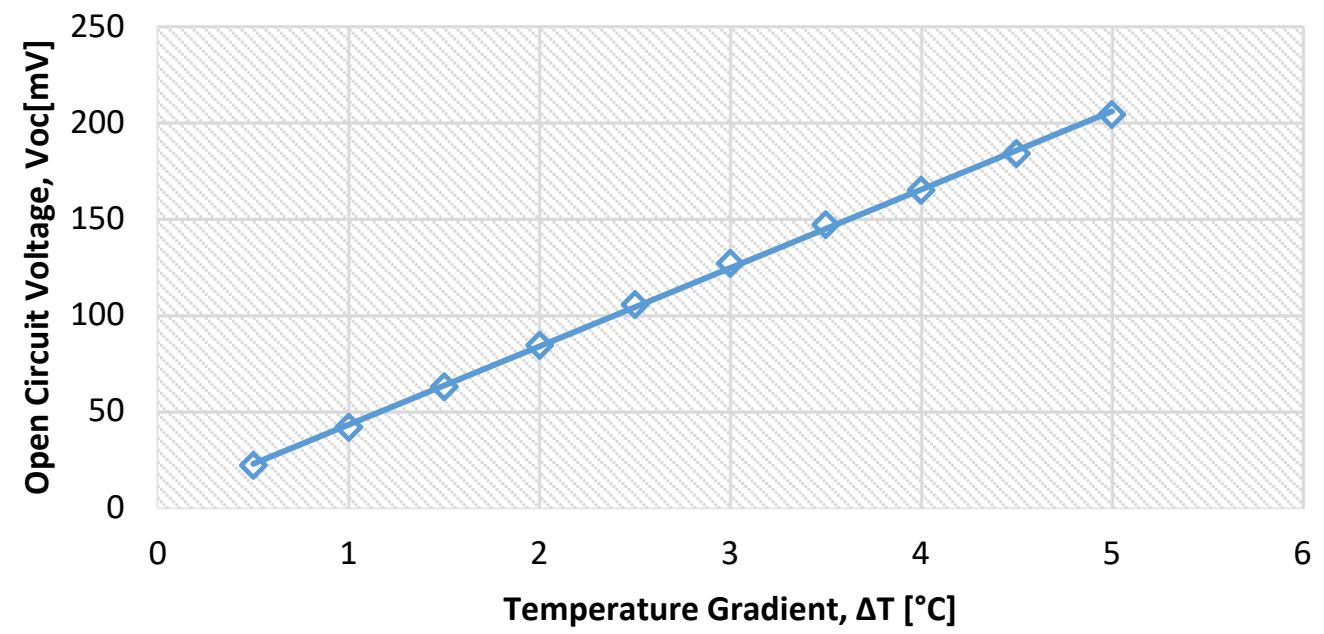

Figure 4. Open circuit testing: $\mathrm{V}_{\mathrm{OC}}$ vs Temperature gradients.

Table 3. Calculated parameters for TEC1-12722.

\begin{tabular}{ccc}
\hline Parameters & Calculated Values & Units \\
\hline $\mathrm{R}_{\mathrm{TEG}}$ & 53 & $\mathrm{mV} / \mathrm{K}$ \\
$\mathrm{Se}$ & 0.692 & $\Omega$ \\
\hline
\end{tabular}

\subsubsection{EHC Model I-V Curves at $2.3 \mathrm{~V}_{\text {OUT }}$}

In order to determine the current versus voltage curves of thermal EHC, the temperature gradients $(\Delta \mathrm{T})$ were varied with the step of 0.5 till the output voltage became stable, whereas, a series of resistive loads $\left(\mathrm{R}_{\mathrm{LOAD}}\right)$ were implemented to measure the output values in terms of current ( $\left.\mathrm{I}_{\mathrm{OUT}}\right)$ and voltage ( $\left.\mathrm{V}_{\text {OUT }}\right)$ as demonstrated in Figure 5.

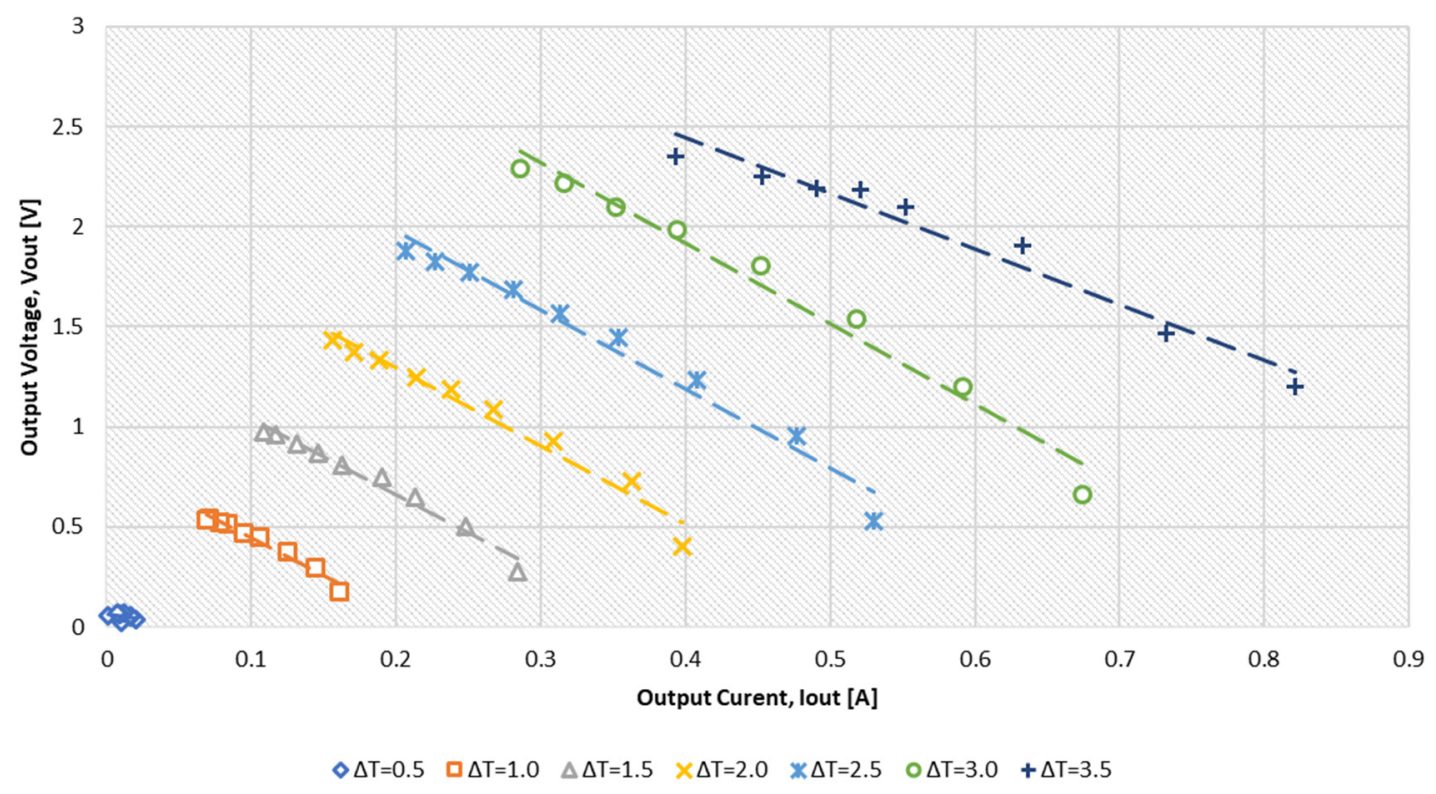

Figure 5. Thermal EHC Output Voltage-Output Current curve at 2.3 V. 
It can be seen that output current ( $\left.\mathrm{I}_{\mathrm{OUT}}\right)$ decreased linearly in the same temperature gradient $(\Delta \mathrm{T})$ whereas with the increase in temperature gradient, the output voltage and output current also increased.

\subsubsection{EHC Model Power Curves at 2.3 V OUT}

For analyzing the power generation from the thermal EHC along with PMIC, the open circuit testing data were used. The direct proportional relation was established between the temperature gradient and the generated power due to the already analyzed data that was collected from the current ( $\left.\mathrm{I}_{\text {OUT }}\right)$ versus voltage $\left(\mathrm{V}_{\text {OUT }}\right)$ curve in the fixed resistive load shown in Figure 5. The generated curves show the behavior of output power ( $\left.\mathrm{P}_{\mathrm{OUT}}\right)$ as a function of output current $\left(\mathrm{I}_{\mathrm{OUT}}\right)$ parametrized in the temperature difference as demonstrated in Figure 6.

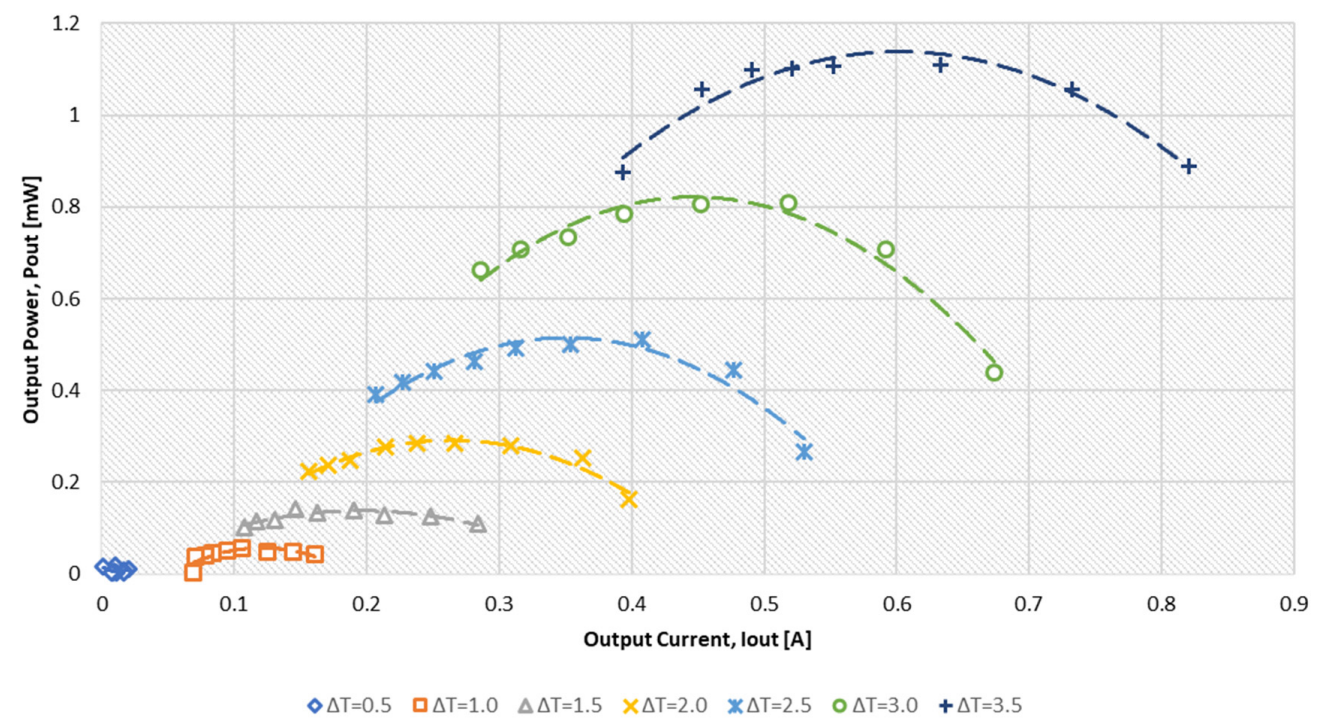

Figure 6. Thermal EHC Output Power-Output Current curve at 2.3 V.

It can be clearly seen that the increase in temperature raised the power generation of EHC, which followed a highly quadratic nature.

Figure 7 shows another way to the power generation curves, where output power ( $\mathrm{P}_{\mathrm{OUT}}$ as a function of output voltage $\left(\mathrm{V}_{\text {OUT }}\right)$ parametrized in various temperature gradients $(\Delta \mathrm{T})$ is simulated.

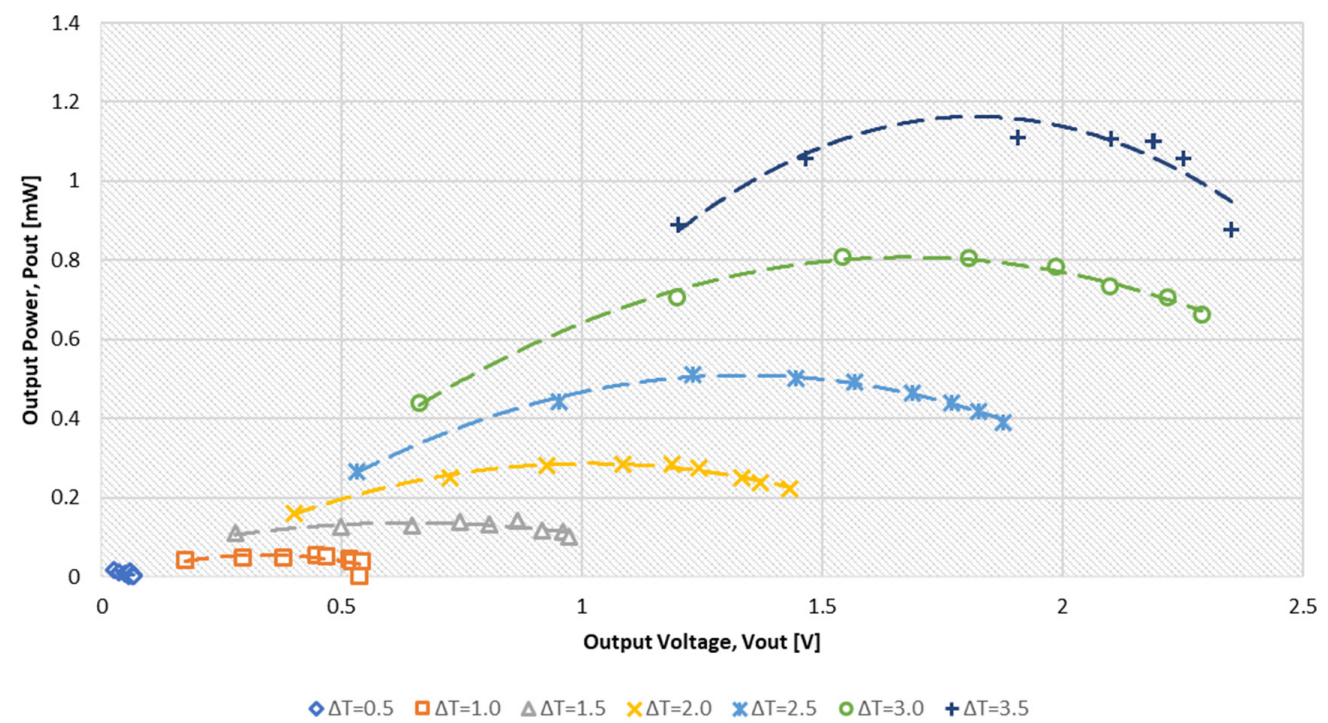

Figure 7. Thermal EHC Output Power-Output Voltage curve at 2.3 V. 


\subsection{Setup 2: Setting $V_{\text {out }}$ at 3.3 V for Thermal EHC}

The same extracted parameters for TEG model were supplied as an input to the thermal EHC except the $\mathrm{V}_{\text {OUT }}$ reference voltage was set at $3.3 \mathrm{~V}$. In this regard, following pin configuration was required by setting VS1 $=$ VAUX and VS2 $=$ GND.

\subsubsection{EHC Model I-V Curves at $3.3 \mathrm{~V}_{\text {OUT }}$}

For determining the current vs. voltage curve of thermal EHC at $3.3 \mathrm{~V}$ setting in PMIC, it can be seen that there exists a linear relationship between current and voltage. It also requires more temperature to reach a stable output voltage $\left(\mathrm{V}_{\mathrm{OUT}}\right)$ as compared to the $2.3 \mathrm{~V}$ setup shown in Figure 8.

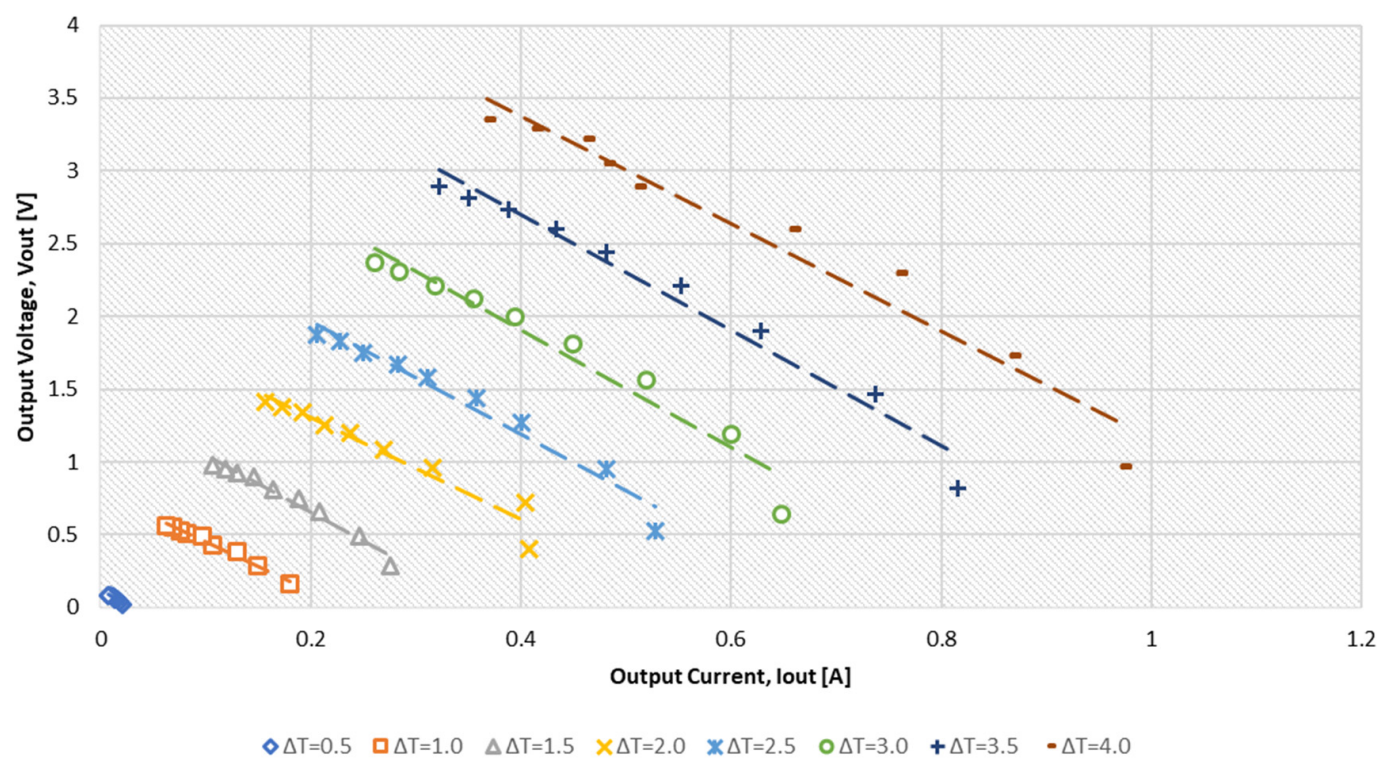

Figure 8. Thermal EHC Output Voltage-Output Current curve at 3.3 V.

\subsubsection{EHC Model Power Curves}

By applying the same parameters except to the $\mathrm{V}_{\text {OUT }}$ setting i.e., $3.3 \mathrm{~V}$, the generated curves established maximum power output when compared to the $2.3 \mathrm{~V}$ settings as shown in Figure 9.

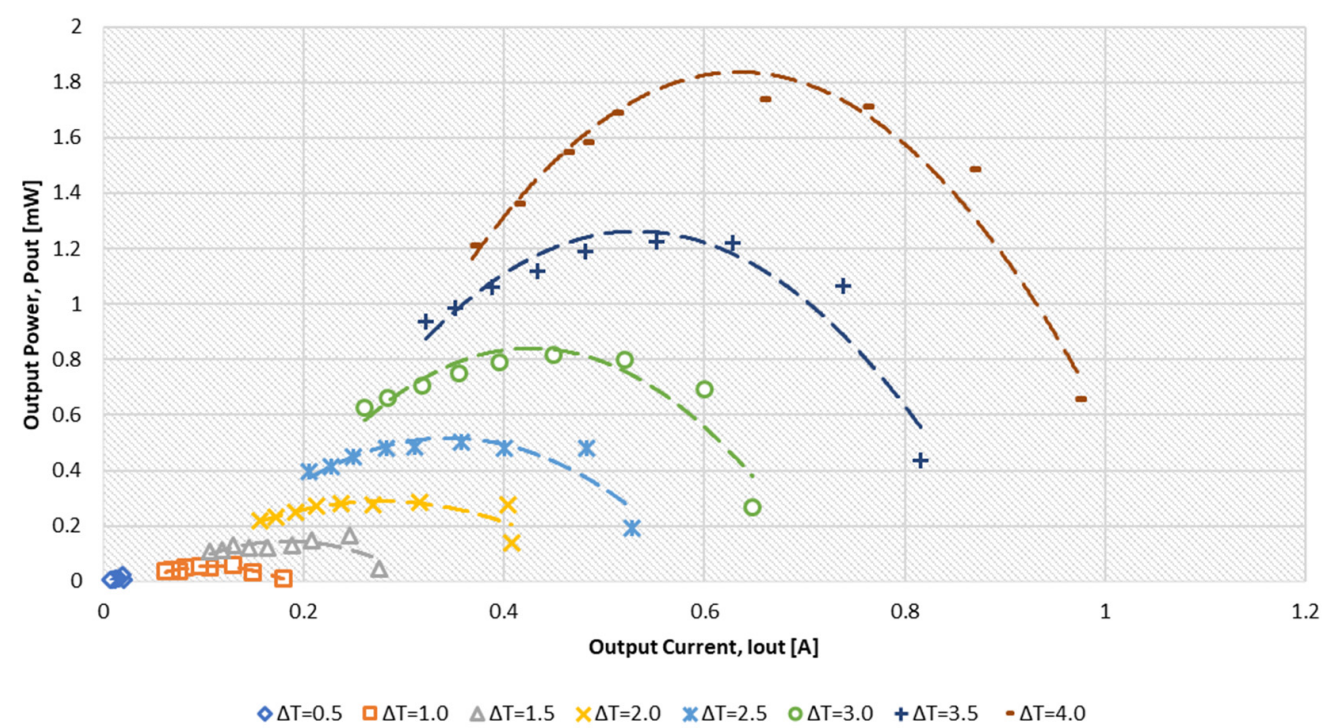

Figure 9. Thermal EHC Output Power-Output Current curve at $3.3 \mathrm{~V}$. 
By analyzing the generated power curve in Figure 10, it is clear that the maximal output power ( $\left.\mathrm{P}_{\mathrm{OUT}}\right)$ was nearly half of the maximal output voltage $\left(\mathrm{V}_{\mathrm{OUT}}\right)$ and this maximum output voltage was equal to the open circuit output. However, in this manner it verified the formula for TEG at maximum power transfer moment [30].

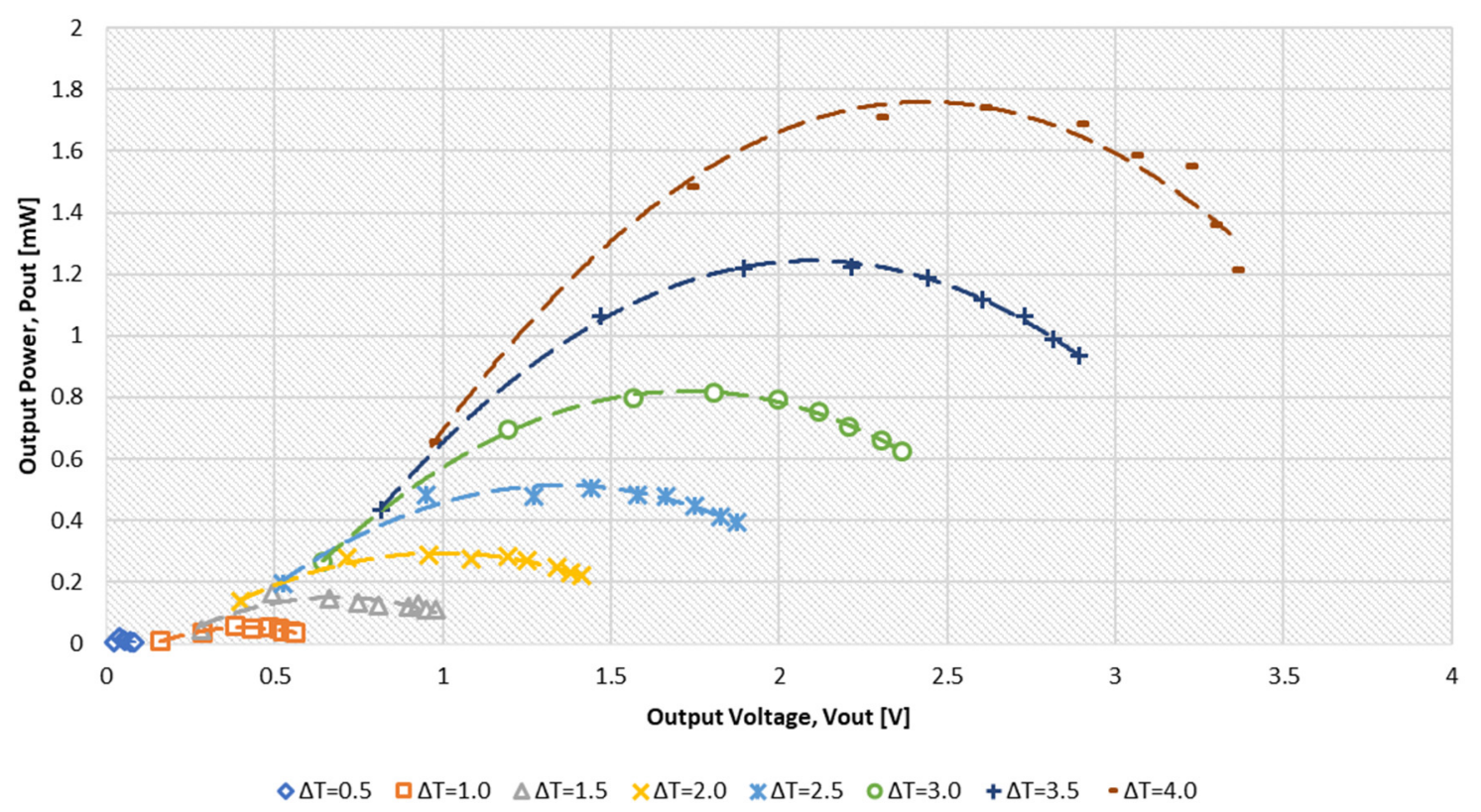

Figure 10. Thermal EHC Output Power-Output Voltage curve at $3.3 \mathrm{~V}$.

\section{Results and Discussion}

The obtained results were evaluated to verify the characteristics and performance of the chosen TEC1-12722 under two scenarios, the first setup generated curves of output voltage and current, which were collected till $3.5^{\circ} \mathrm{C}$, as according to the LTC3108 capability, it could stabilize the $2.3 \mathrm{~V}$ output at this temperature. The maximum generated power went till $\mathrm{P}_{\mathrm{MAX}}=1.098 \mathrm{~mW}\left(\mathrm{I}_{\mathrm{MAX}}=0.467 \mathrm{~mA}\right.$, $\mathrm{V}_{\text {MAX }}=2.353 \mathrm{~V}$ ). On the second scenario, it took a $4.0^{\circ} \mathrm{C}$ temperature to stabilize the output voltage to $3.3 \mathrm{~V}$. By analyzing the power curves, we found out that the maximum generated power went till $\mathrm{P}_{\text {MAX }}=1.719 \mathrm{~mW}\left(\mathrm{I}_{\mathrm{MAX}}=0.521 \mathrm{~mA}, \mathrm{~V}_{\mathrm{MAX}}=3.3 \mathrm{~V}\right)$. Considering the power generation result of the prototype with power consumption for IoT, this generated power could be compared with the required power of IoT components mentioned in Tables 1 and 2. Currently, this prototype was not experimentally tested with the required power consumption of IoT, but we contrasted the results as approximations to at least generalize the power consumption. However, the average power requirement by wearables vary from $\mu \mathrm{W}$ to $\mathrm{mW}$ as already reported [31] and the results obtained from the simulation authenticated the hypothesis that TEG could fulfil this demand as a power source. In terms of performance analysis of commercially available TEGs, this study was compared with regard to power generation specifically on the type of TEG and material that came under consideration (for simulation and experimental studies so far), when it came to designing a human wearable device. The commercially available TEGs were analyzed based on efficiency and the suitability of supporting EH-based wearable devices. In this regard, Peter et. al [32] presented a comparative analysis of three different types of TEGs; (a) TEG2-126LDT (BiTe TEG) [33], (b) TEG2-07025HT-SS (BiTe TEG) [34], and (c) TEG1-PB-12611-6.0 (BiTe and PbTe hybrid) [35], where each model pertained to specific combinations of temperature, resistance and voltage values. Based upon measurement results and the power needs of wearable devices the TEG optimized for low temperature i.e., TEG2-126LDT provided an optimal power level for wearable devices. Another study [36] presented a prototype for an autonomous wireless sensor with a low cost TEG, and was experimented with TEC1-12706 along with LTC3108 PMIC, where this prototype was able to power the autonomous sensor. A practical experiment was demonstrated using 
TEC1-12706 with LTC3108 PMIC where authors claimed to charge a wearable device using human body heat [37]. Therefore, according to the available reported solutions, mostly TEC1-12706 has presented their results based on suitability and efficiency whereas, TEG2-126LDT which is specifically prepared for lower temperature difference, also proved to be an efficient solution for wearable devices. Nevertheless, it depends on the end user when designing any thermal EHC while considering the prerequisite of the application, selection of appropriate transducer, power management solutions and voltage ratings of the specific device.

\section{Conclusions}

The goal of this simulation study was the experimental characterization of the performance of a commercially available thermoelectric cooler used as a generator for validating the usage in harvesting human body heat for wearable IoT applications. Two different setups were developed, and controlled measurements were carried out at different load configurations and varying temperature gradients. This enabled the study of the behavior and performance of complete TEG-based thermal EHC incorporated with PMIC under strict operating conditions, which could be found similarly in energy harvesting applications.

It can be concluded that the measured result from commercially available TEC1-12722 under energy harvesting principles and power management setup produced typical power levels which could be suitable for some of the IoT components and applications. This simulation-based study needs to be further experimented under real time scenarios, where actual human body heat could be captured and transformed under various states. Currently, this study has made a basis for the performance and behavior of TEG as a prototype before implementing the real physical system and can be used for any other TEGs with improved criterion such as extracting thermal parameters (Cq, Rq) based on a trial and error study of simulation and then benchmarking it with actual TEG measurements conducted experimentally, could enhance the performance of the EHC system However, in terms of optimization and reusability this prototype could be improved by various means like calculation of thermal characteristics, using more efficient TEG, working on different $\mathrm{V}_{\text {OUT }}$ settings $(4.1 \mathrm{~V}, 5 \mathrm{~V})$, and analyzing the sustainability of PMIC under various $\mathrm{R}_{\text {LOAD }}$ conditions. This simulation-based analysis could be used as a point of reference for studies which require understanding towards power generation by the transducer connected with PMIC and power consumption analysis. As a result, this study provides an insight for an initial and step by step basis for developing any thermal based IoT prototype for specific applications.

Author Contributions: S.A.A. conducted research, established the methodology and participated in the writing of the paper; H.G. did the formal analysis and review of the paper.

Funding: This research received no external funding.

Conflicts of Interest: The authors declare no conflicts of interest.

\section{References}

1. Sarkar, S. Chapter 11 - Internet of Things-robustness and reliability. In Internet of Things: Principles and Paradigms; Buyya, R., Vahid Dastjerdi, A., Eds.; Morgan Kaufmann: Burlington, MA, USA, 2016; pp. $201-218$. ISBN 978-0-12-805395-9.

2. Krasniqi, X.; Hajrizi, E. Use of IoT Technology to Drive the Automotive Industry from Connected to Full Autonomous Vehicles. IFAC-PapersOnLine. 2016, 49, 269-274. [CrossRef]

3. Mukhopadhyay, S.C.; Suryadevara, N.K. Internet of Things: Challenges and Opportunities. In Internet of Things: Challenges and Opportunities; Mukhopadhyay, S.C., Ed.; Springer International Publishing: Cham, The Netherlands, 2014; pp. 1-17. ISBN 978-3-319-04223-7.

4. Kåberger, T. Progress of renewable electricity replacing fossil fuels. Glob. Energy Interconnect. 2018, 1, 48-52. 
5. Aksanli, B.; Rosing, T.S.; Monga, I. Benefits of Green Energy and Proportionality in High Speed Wide Area Networks Connecting Data Centers. In Proceedings of the Proceedings of the Conference on Design, Automation and Test in Europe, Dresden, Germany, 12-16 March 2012; EDA Consortium: San Jose, CA, USA, 2012; pp. 175-180.

6. Dewan, A.; Ay, S.U.; Karim, M.N.; Beyenal, H. Alternative power sources for remote sensors: A review. J. Power Sources 2014, 245, 129-143. [CrossRef]

7. Maharaj, S.; Govender, P. Waste energy harvesting with a thermoelectric generator. In Proceedings of the 2013 Proceedings of the 21st Domestic Use of Energy Conference, Cape Town, South Africa, 3-4 April 2013; pp. 1-6.

8. Snyder, G.J. Thermoelectric Energy Harvesting. In Energy Harvesting Technologies; Priya, S., Inman, D.J., Eds.; Springer: Boston, MA, USA, 2009; pp. 325-336. ISBN 978-0-387-76464-1.

9. Dziurdzia, P. Modeling and Simulation of Thermoelectric Energy Harvesting Processes. In Sustainable Energy Harvesting Technologies; Tan, Y.K., Ed.; IntechOpen: Rijeka, Croatia, 2011.

10. Srinivasan, B.; Gellé, A.; Gucci, F.; Boussard-Pledel, C.; Fontaine, B.; Gautier, R.; Halet, J.-F.; Reece, M.J.; Bureau, B. Realizing a stable high thermoelectric zT $\sim 2$ over a broad temperature range in Ge1-x-yGaxSbyTe via band engineering and hybrid flash-SPS processing. Inorg. Chem. Front. 2019, 6, 63-73. [CrossRef]

11. Zhang, X.; Zhao, L.-D. Thermoelectric materials: Energy conversion between heat and electricity. J. Materiomics 2015, 1, 92-105. [CrossRef]

12. Srinivasan, B.; Fontaine, B.; Gucci, F.; Dorcet, V.; Saunders, T.G.; Yu, M.; Cheviré, F.; Boussard-Pledel, C.; Halet, J.-F.; Gautier, R.; et al. Effect of the Processing Route on the Thermoelectric Performance of Nanostructured CuPb18SbTe20. Inorg. Chem. 2018, 57, 12976-12986. [CrossRef] [PubMed]

13. Mateu, L.; Codrea, C.; Lucas, N.; Pollak, M.; Spies, P. Human Body Energy Harvesting Thermogenerator for Sensing Applications. In Proceedings of the 2007 International Conference on Sensor Technologies and Applications (SENSORCOMM 2007), Valencia, Spain, 14-20 October 2007; pp. 366-372.

14. Kotanagi, S. Thermoelectric generation unit and portable electronic device using the unit. U.S. Patent No. US6560167B1, 6 May 2003.

15. Curry, J.; Harris, N. Powering the Environmental Internet of Things. Sensors 2019, 19, 1940. [CrossRef] [PubMed]

16. Sachan, V.K.; Imam, S.A.; Beg, M.T. Energy-efficient Communication Methods in Wireless Sensor Networks: A Critical Review. International Journal of Computer Applications 2012, 39, 35-48.

17. Natsui, M.; Suzuki, D.; Tamakoshi, A.; Watanabe, T.; Honjo, H.; Koike, H.; Nasuno, T.; Ma, Y.; Tanigawa, T.; Noguchi, Y.; et al. 12.1 An FPGA-Accelerated Fully Nonvolatile Microcontroller Unit for Sensor-Node Applications in 40nm CMOS/MTJ-Hybrid Technology Achieving 47.14 $\mu$ W Operation at 200MHz. In Proceedings of the 2019 IEEE International Solid- State Circuits Conference - (ISSCC), San Francisco, CA, USA, 17-21 February 2019; pp. 202-204.

18. Nesarajah, M.; Frey, G. Thermoelectric power generation: Peltier element versus thermoelectric generator. In Proceedings of the IECON 2016 - 42nd Annual Conference of the IEEE Industrial Electronics Society, Florence, Italy, 23-26 October 2016; pp. 4252-4257.

19. Hebei, I.T. (Shanghai) Co., Ltd. Thermoelectric Cooler, TEC1-12706. Available online: http://www.hebeiltd. com.cn/peltier.datasheet/TEC1-12706.pdf (accessed on 17 August 2019).

20. Thermoelectric Generator Module: GM250-127-14-10. Available online: https://www. europeanthermodynamics.com/products/datasheets/GM250-127-14-10-v2.pdf (accessed on 15 July 2019).

21. Thermonamic Module: TEC1-12722. Available online: http://www.thermonamic.com/TEC1-12722-English. pdf (accessed on 15 July 2019).

22. Siouane, S.; Jovanović, S.; Poure, P. Equivalent Electrical Circuits of Thermoelectric Generators under Different Operating Conditions. Energies 2017, 10, 386. [CrossRef]

23. Ando, O.H., Jr.; Izidoro, C.L.; Gomes, J.M.; Correia, J.H.; Carmo, J.P.; Schaeffer, L. Acquisition and Monitoring System for TEG Characterization. Int. J. Distrib. Sens. Netw. 2015, 11, 531516. [CrossRef]

24. Ando Junior, O.H.; Calderon, N.H.; De Souza, S.S. Characterization of a Thermoelectric Generator (TEG) System for Waste Heat Recovery. Energies 2018, 11, 1555. [CrossRef]

25. Kubov, V.I.; Dymytrov, Y.Y.; Kubova, R.M. LTspice-model of thermoelectric Peltier-Seebeck element. In Proceedings of the 2016 IEEE 36th International Conference on Electronics and Nanotechnology (ELNANO), Kiev, Ukraine, 19-21 April 2016; pp. 47-51. 
26. Moumouni, Y.; Baker, R.J. Improved SPICE modeling and analysis of a thermoelectric module. In Proceedings of the 2015 IEEE 58th International Midwest Symposium on Circuits and Systems (MWSCAS), Fort Collins, CO, USA, 2-5 August 2015; pp. 1-4.

27. Kubov, V.I.; Dymytrov, Y.Y. Simple method of thermoelectric cooler (Peltier device) parameters determination based on datasheet and modeling results. Available online: https://www.researchgate.net/publication/ 316658067_Simple_method_of_thermoelectric_cooler_Peltier_device_parameters_determination_based_ on_datasheet_and_modeling_results (accessed on 14 May 2019).

28. LTC3108 Dual TEG Energy Harvester (3.3V/2.2V) Operates from Temperature Differentials of Either Polarity Circuit Collection | Analog Devices. Available online: https://www.analog.com/en/design-center/referencedesigns/circuit-collections/ltc3108-dual-teg-energy-harvester-3-3v-2-2v-operates-from-temperaturedifferentials-of-either.html\#cc-documentation (accessed on 10 July 2019).

29. Magno, M.; Brunelli, D.; Sigrist, L.; Andri, R.; Cavigelli, L.; Gomez, A.; Benini, L. InfiniTime: Multi-sensor wearable bracelet with human body harvesting. Sustain. Comput. Inform. Syst. 2016, 11, 38-49. [CrossRef]

30. Montecucco, A.; Knox, A.R. Maximum Power Point Tracking Converter Based on the Open-Circuit Voltage Method for Thermoelectric Generators. IEEE Trans. Power Electron. 2015, 30, 828-839. [CrossRef]

31. Schmidt, C.L.; Skarstad, P.M. The future of lithium and lithium-ion batteries in implantable medical devices. J. Power Sources 2001, 97-98, 742-746. [CrossRef]

32. Gljuscic, P.; Zelenika, S.; Kamenar, E. Characterisation of Performances of Thermoelectric Generators for Energy Harvesting Applications. In DAAAM Proceedings; Katalinic, B., Ed.; DAAAM International: Vienna, Austria, 2018; Volume 1, pp. 0025-0030. ISBN 978-3-902734-20-4.

33. TEG2-126LDT for Body \& Sensor Power Thermoelectric Harvesting Applications. Available online: https: //tecteg.com/wp-content/uploads/2015/01/TEG1-PB-12611-6.0_CBH-1-Final-November-17th-update.pdf (accessed on 2 September 2019).

34. TEG2-07025HT-SS liquid to liquid applications. Available online: https://espressomilkcooler.com/wp-content/ uploads/2014/05/Spec-TEG2-07025HT-SS-rev1.pdf (accessed on 2 September 2019).

35. TEG1-PB-12611-6.0_CBH-1 TECTEG Power Generation. Available online: https://tecteg.com/ wp-content/uploads/2015/01/TEG1-PB-12611-6.0_CBH-1-Final-November-17th-update.pdf (accessed on 2 September 2019).

36. Costa, A.; Costa, D.; Morgado, J.; Santos, H.; Ferreira, C. Autonomous Wireless Sensor with a Low Cost TEG for Application in Automobile Vehicles. Procedia Eng. 2014, 87, 1226-1229. [CrossRef]

37. Raheem, A.; Sai Rakesh, D.; Srinivasa Reddy, K.; Srikanth, K. Wireless Charge of Wearable Device Using Human Warmth; V.R. SIDHARTHA ENGINEERING COLLEGE: Vijayawada, India, 2019. 